\title{
Relating fundamental creep mechanisms in Waspaloy to the Wilshire equations
}

\author{
C. Deen ${ }^{1, a}$, M.T. Whittaker ${ }^{1}$, W. Harrison ${ }^{1}$, C.M.F. Rae ${ }^{2}$, and S.J. Williams ${ }^{3}$ \\ ${ }^{1}$ Swansea University, Swansea, GB \\ ${ }^{2}$ Cambridge University, Cambridge, GB \\ ${ }^{3}$ Rolls-Royce plc., Derby, GB
}

\begin{abstract}
Creep tests of the polycrystalline nickel alloy Waspaloy have been conducted at Swansea University, for varying stress conditions at $700{ }^{\circ} \mathrm{C}$. Investigation through use of Transmission Electron Microscopy at Cambridge University has examined the dislocation networks formed under these conditions, notably those with stresses above and below the yield stress. This paper highlights how the dislocation structures vary throughout creep and proposes a dislocation mechanism theory for creep in Waspaloy. In particular, the roles of recovery, tertiary gamma prime particles and dislocation foresting are examined, and related back to observations from the Wilshire fits. The virgin (untested) material has been forged and heat treated, containing some recrystallised material together with areas of more heavily deformed and recovered material clustered around the grain boundaries. Observations from tests below the $0.2 \%$ proof stress show relatively low dislocation densities away from grain boundaries and dislocation movement can be seen to be governed by interactions with the $\gamma^{\prime}$ precipitates. In contrast, above the $0.2 \%$ proof stress, TEM observations show a substantially greater density of dislocations. The increased density provides an increment of strength through forest hardening. At stresses above the original yield point, determined by the precipitates, the creep rate is controlled by inter-action with the dislocation forest and results in an apparent activation energy change. It is proposed that the activation energy change is related to the stress increment provided by work hardening, as can be observed from $\mathrm{Ti}$, Ni and steel results.
\end{abstract}

\section{Introduction}

The material phenomenon of creep, and more precisely, the prediction of long term behaviour based on short term experiments, has become one of the most important challenges to the UK Energy Sector, according to the Materials UK Energy Review 2007 [1]. Material creep has been the subject of extensive research for more than half a century, yet no single approach in the field of high temperature creep proposed during this time has been widely accredited with accomplishing the goals established during the Energy Review. More recent methodologies still fail to link the micromechanical behaviour to macroscopic properties and material behaviour.

Traditional methods of creep lifing have been derived from power law equations, containing an Arrhenius term, in which the minimum creep rate $\left(\dot{\varepsilon}_{m}\right)$ is related to the rupture life $\left(\mathrm{t}_{f}\right)$ through the Monkman-Grant relationship [2]

$$
M / t_{f}=\varepsilon_{\mathrm{m}}=A \sigma^{n} \exp \left(-Q_{c} / R T\right)
$$

where $\mathrm{R}$ is the molar gas constant $\left(8.314 \mathrm{Jmol}^{-1} \mathrm{~K}^{-1}\right)$, $\mathrm{A}$ and $\mathrm{M}$ are constants, $\mathrm{T}$ is the temperature and $\sigma$

\footnotetext{
${ }^{a}$ Corresponding author: $481652 @$ swansea.ac.uk
}

is the stress. Originally proposed as constants, however, the stress exponent $(\mathrm{n})$ and the activation energy $\left(\mathrm{Q}_{c}\right)$ vary depending upon the applied stress and temperature. The dominant creep mechanism is then determined by comparing the experimentally measured values of $n$ and $\mathrm{Q}_{c}$ to those theoretically predicted. In pure metals, a stress exponent change from $\mathrm{n} \cong 4$ to $\mathrm{n} \cong 1$ with decreasing stress and an activation energy change from $\mathrm{Q}_{\mathrm{c}}=\mathrm{Q}_{\mathrm{SD}}$ to $\mathrm{Q}_{c}=0.5 \mathrm{Q}_{\mathrm{SD}}$ with increasing temperature occurs $\left(\mathrm{Q}_{\mathrm{SD}}\right.$ is the activation energy for lattice self-diffusion), inferring different active creep mechanisms [3].

The reduction in stress exponent is widely attributed to a change from diffusion-controlled dislocation processes to creep mechanisms related to vacancy diffusion, whereas the reduction in activation energy is associated with a change from Nabarro-Herring creep to Coble creep [3].

In alloys strengthened by dispersions of fine precipitates or insoluble particles, such as Waspaloy, at high stress, it is not uncommon for values of the stress exponent to greatly exceed those found in pure metals, $n>>4$, and Qc can exceed $\mathrm{Q}_{\mathrm{SD}}$. No generally accepted interpretation of this 'power law breakdown' has been agreed to account for these anomalously large values [4].

In 1962 Sherby showed that at intermediate stresses, values for the stress exponent of 4-6 are generally found irrespective of crystal structure or stacking fault

This is an Open Access article distributed under the terms of the Creative Commons Attribution License 4.0, which permits unrestricted use, distribution, and reproduction in any medium, provided the original work is properly cited. 
Table 1. Composition of Waspaloy (in wt\%).

\begin{tabular}{|l|l|l|l|l|l|l|l|}
\hline $\mathrm{Cr}$ & $\mathrm{Co}$ & $\mathrm{Mo}$ & $\mathrm{Al}$ & $\mathrm{Ti}$ & $\mathrm{C}$ & $\mathrm{B}$ & $\mathrm{Ni}$ \\
\hline 19.5 & 13.5 & 4.3 & 1.3 & 3 & 0.08 & 0.006 & $\mathrm{Bal}$ \\
\hline
\end{tabular}

energy. This implies that the dominant creep mechanism is similar for each material [5]. This behaviour is rationalised by Daehn and Brehm [6], in a model based on dislocation climb within a cell structure determined by the equilibrium between recovery and dislocation generation. In addition, recently the contribution of non-dislocation based diffusional creep to the overall deformation has been questioned. This has led to the widely upheld conclusion that at intermediate stresses, the dominant creep mechanism is diffusion-controlled dislocation movement [7].

The Wilshire equations have been successfully utilised to accurately predict the creep life of several different materials, including pure copper, nickel alloys, titanium alloys and power generation steels. The equation governing minimum creep rate is governed by

$$
\left(\sigma / \sigma_{T S}\right)=\exp \left\{-k_{2}\left[\dot{\varepsilon}_{m} \exp \left(Q_{C}^{*} / R T\right)\right]^{v}\right\} .
$$

Using this method for a variety of different materials has resulted in the observation of discontinuities in the constants for the Wilshire equations where these are derived by the best fit. These "break points" mark an abrupt transition in behaviour, whether plotted in terms of minimum creep rate or rupture time as a function of stress. This break point is commonly found to occur at stresses approximately equal to the yield stress of the material.

\section{Experimental methods}

The material selected for the programme was Waspaloy (a registered trademark of Pratt \& Whitney Aircraft). It is a precipitation hardened alloy which was developed from the Nimonic series of alloys. It has considerable strength and corrosion resistance at temperatures up to $870{ }^{\circ} \mathrm{C}$ above which intergranular oxidation compromises performance. The chemical composition of Waspaloy (in wt\%) [8] is shown in Table 1.

The samples of Waspaloy used for testing were taken from a disc forging, which had a typical heat treatment of $995-1040{ }^{\circ} \mathrm{C}$ for 4 hours, air cooled, followed by a stabilisation period at $845^{\circ} \mathrm{C}$ for 4 hours, air cooled, and aged at $760^{\circ} \mathrm{C}$ for 16 hours, air cooled.

Creep testing was completed in air on a Mayes constant stress creep machine with a loading lever ratio of $15: 1$ for stresses above $10 \mathrm{MPa}$ (discounting the onset of tertiary failure and necking). Specimen strains were monitored using extensometers incorporating a pair of ASL differential capacitance transducers capable of resolving changes in gauge length to $10 \mathrm{~nm}$.

Testing for TEM analysis, was carried out at $700{ }^{\circ} \mathrm{C}$ (973 K) measured using two R type thermocouples. All loading, temperature and strain monitoring systems are calibrated annually, in line with BS EN ISO 7500-2 and BS EN ISO 9513.

For examination under TEM, most tests were stopped at the minimum strain rate condition, frequently

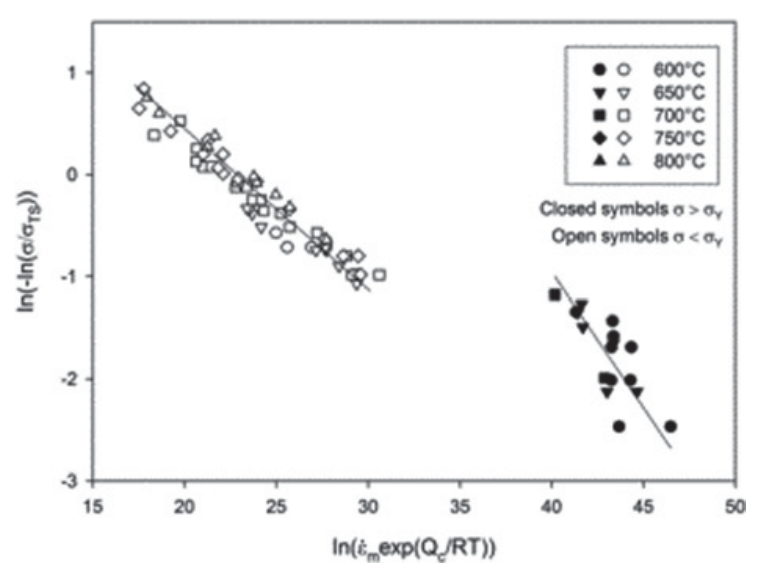

Figure 1a. Derivation of the constants utilised in the Wilshire Equations.

recalculated during test progression, using the secant method. They were air cooled under reduced load to preserve the dislocation structures. Specimens were machined down from a standard specimen with diameter $3.57 \mathrm{~mm}$ to a $3 \mathrm{~mm}$ gauge diameter prior to testing. In one test, at $800 \mathrm{MPa}$, the test was stopped at $1 \%$ creep strain accumulation, and furnace cooled without load. In this case, the standard specimen with gauge diameter $3.57 \mathrm{~mm}$ was used, the diameter was reduced once thin disc samples had been produced, using spark erosion to reduce the diameter to $3 \mathrm{~mm}$.

In preparation for TEM analysis thin discs were cut from within the gauge length of the crept specimen, to an approximate thickness of $0.5 \mathrm{~mm}$ to $1 \mathrm{~mm}$, using a high precision cutting wheel. These discs were then mounted onto a grinding tool using MWH135 mounting wax. The discs were then progressively ground using grit 800,1200 and 1500 grade paper to a thickness of $150-200 \mu \mathrm{m}$. The thin discs were then subjected to twin-jet electropolishing using a solution of $10 \mathrm{vol} \%$ perchloric acid in methanol at $-5^{\circ} \mathrm{C}$ and $20.5 \mathrm{~V}$.

\section{Results}

When a dataset of a parallel series of tests to rupture, is analysed using the Wilshire Equations, a trend is observed, where stresses above and below the yield stress of the material have different associated constants describing mechanical behaviour, Fig. 1a.

A linear relationship for 'high stress' data can be observed in the current material for which $\mathrm{v}=-0.24 \mathrm{k}_{2}=$ 434 and $\mathrm{Q}_{\mathrm{c}}^{*}=400 \mathrm{kJmol}^{-1}$, with a second line accurately fitting lower stress data where $\mathrm{v}=72 \mathrm{k}_{2}=-0.14$ and $\mathrm{Q}_{\mathrm{c}}{ }^{*}=340 \mathrm{~kJ} \mathrm{~mol}^{-1}$. Predictions made by the equation are shown in Fig. $1 \mathrm{~b}$.

\section{TEM results}

In order to understand the nature of this change a series of creep tests were undertaken at graded levels of stress and at $700{ }^{\circ} \mathrm{C}$, targeted to investigate changing dislocation structures at the onset of yield. 


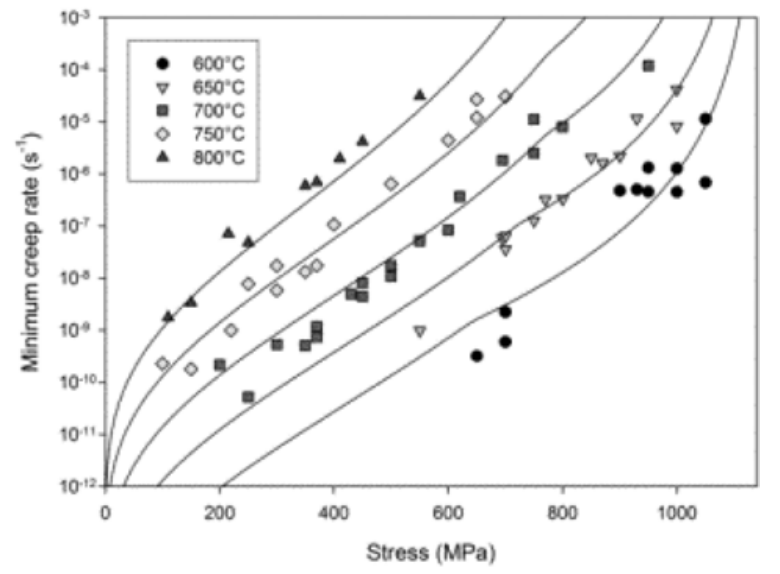

Figure 1b. Wilshire Equation predictions for Waspaloy data.

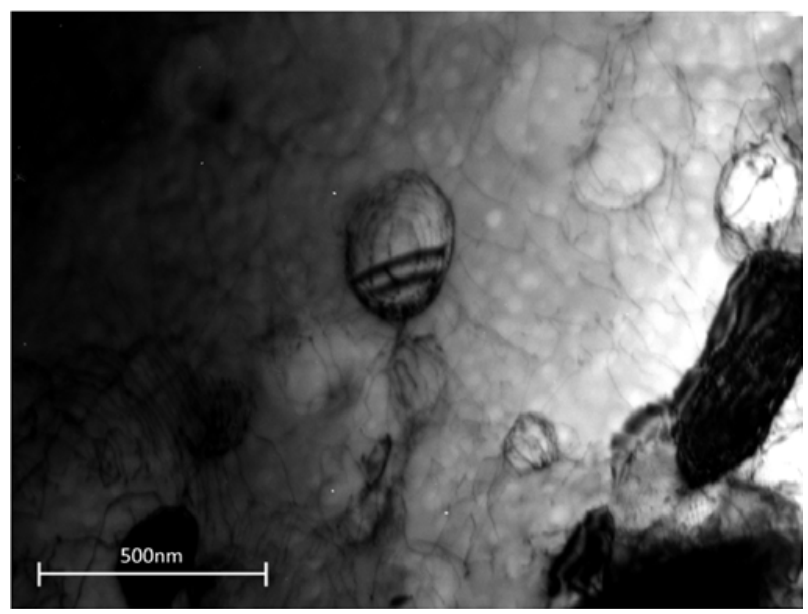

Figure 2a. Dislocation structure in as-received Waspaloy material in the grains.

\subsection{Virgin material}

Figures $2 \mathrm{a}$ and $2 \mathrm{~b}$ show the dislocation structure of the asreceived material under transmission electron microscopy. In Fig. 2a a bimodal distribution of $\gamma^{\prime}$ precipitates is visible with the secondary precipitates approximately $200 \mathrm{~nm}$ in diameter and the tertiary of the order of $50 \mathrm{~nm}$ diameter. Dislocations are visible in the $\gamma$ matrix at moderate density but they generally avoid passing through the larger secondary precipitates, wrapping around in loose networks. The microstructure is consistent with the thermo-mechanical processing route.

Figure $3 \mathrm{~b}$ shows an area straddling a grain boundary. At the boundaries there is evidence of additional strain which has undergone significant recovery to produce a series of sub-grains separated by low angle boundaries. Carbides are visible on the grain boundary.

\section{2. $0.2 \%$ proof stress}

In order to identify the separate effects of creep and plasticity, a monotonic tensile test was halted at the approximate $0.2 \%$ proof stress $(740 \mathrm{MPa})$ of Waspaloy at $700{ }^{\circ} \mathrm{C}$, unloaded and removed from the test machine. The dislocation structure mid-grain and at the boundaries can be seen in Figs. 3a and 3b. Mid-grain there is an increase in

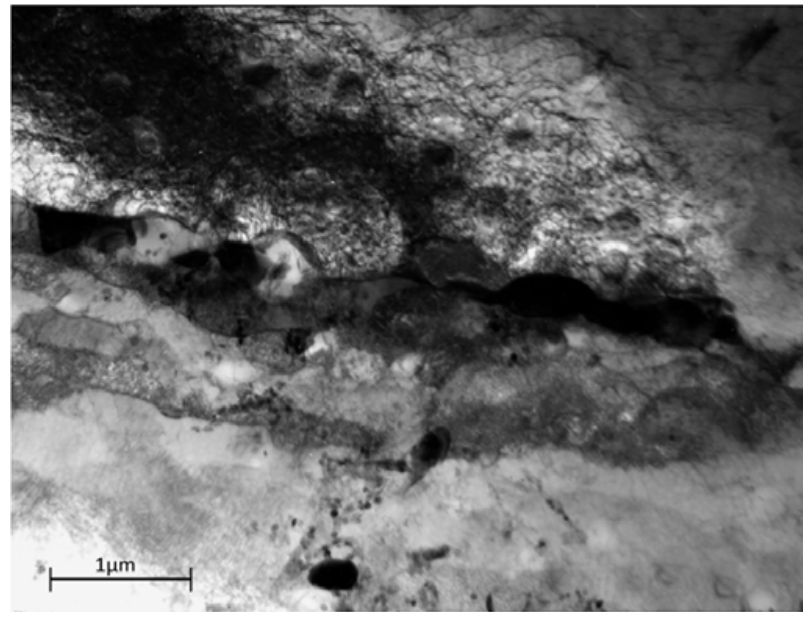

Figure 2b. Dislocation structure in as-received Waspaloy material in the grain boundary zone.

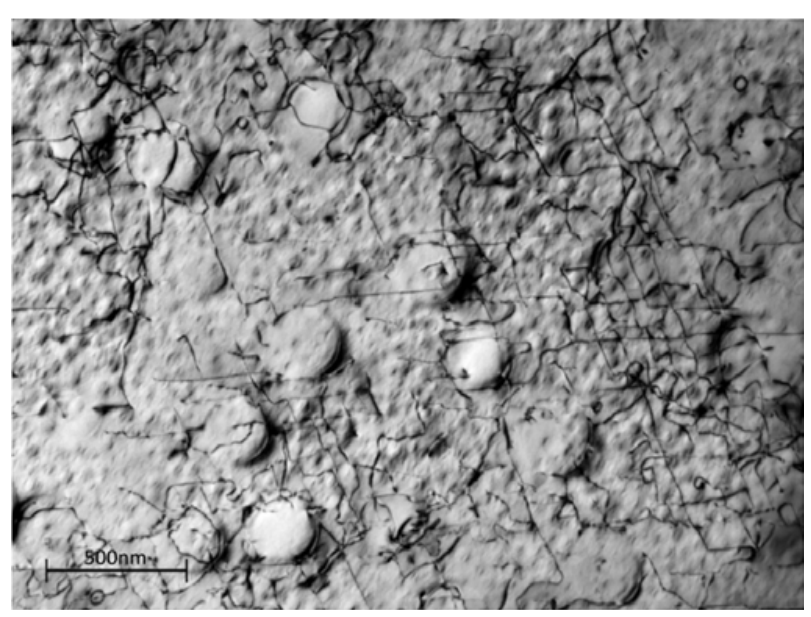

Figure 3a. Dislocation structure in Waspaloy subjected to loading to $0.2 \%$ proof stress in the grains.

the dislocation density, as appropriate sources are activated at the yield point. The dislocations are looping around the secondary precipitates, but for the most part, are cutting through the tertiary $\gamma^{\prime}$ as single dislocations with the exception of some of the larger precipitates: an example of this is evident in the top right of Fig. 3a. There is no evidence of stacking faults in any part of the microstructure and it is interesting to note that the dislocations do not appear to be moving in pairs.

Figure $3 \mathrm{~b}$ shows the grain boundary area of the yielded sample. The low angle sub-grains remain as in the virgin material.

\section{3. $500 \mathrm{MPa}$ condition}

A creep test performed at $500 \mathrm{MPa}$ and $700{ }^{\circ} \mathrm{C}$ was interrupted at $21 \mathrm{~h}(0.25 \%$ creep strain $)$, the time associated with the minimum strain rate from a similar test to rupture. At this point the dislocation structures should be fully evolved but the effects of tertiary behaviour avoided.

Figures $4 \mathrm{a}$ and $4 \mathrm{~b}$ show the TEM images for the dislocation structure at this creep condition. In the grain centres the dislocation density is relatively low and those 


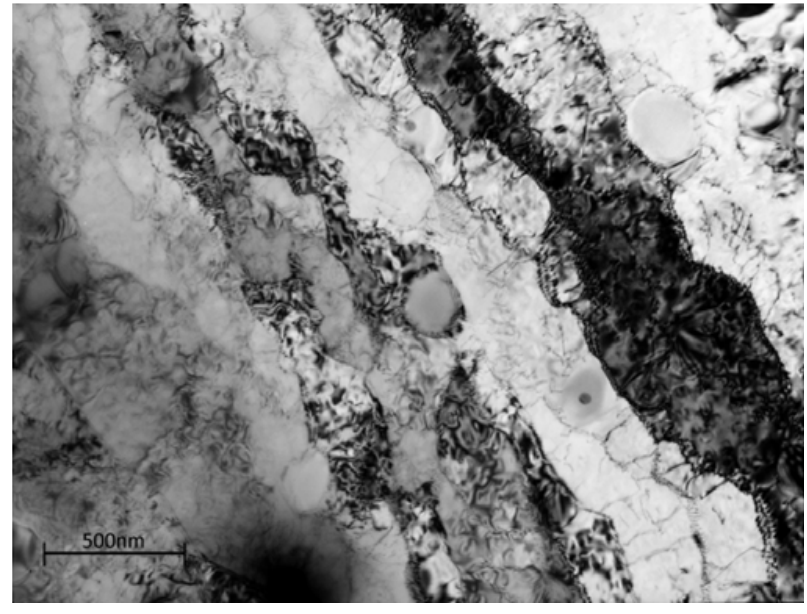

Figure 3b. Dislocation structure in Waspaloy subjected to loading to $0.2 \%$ proof stress in the GBZ.

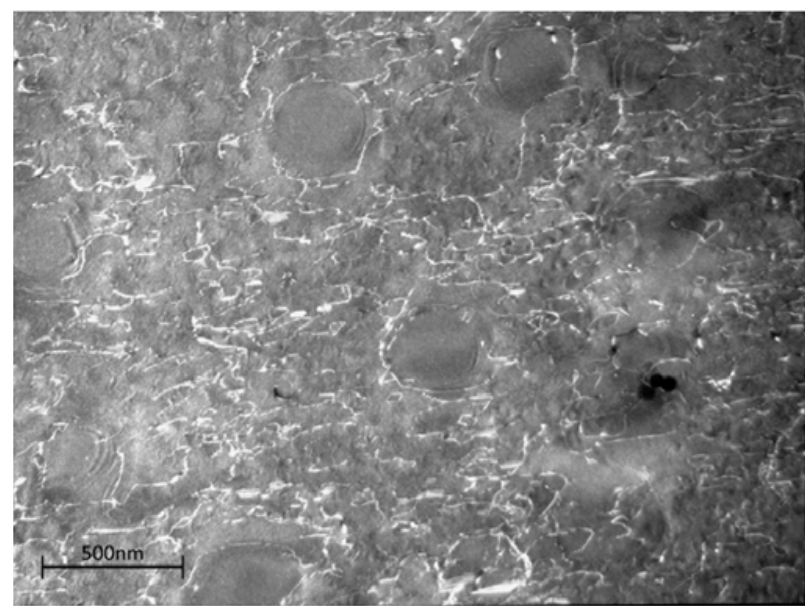

Figure 4a. Dislocation structure in Waspaloy subjected to creep loading at $500 \mathrm{MPa}$ in the grains.

present are hindered by the $\gamma^{\prime}$. There are frequent instances of Orowan looping around not only all the secondary $\gamma^{\prime}$, but also the larger tertiary $\gamma^{\prime}$ and occasional instances of stacking faults in the tertiary $\gamma^{\prime}$.

The grain boundary zones at this condition retain the sub-grain structure of the virgin material, but also show similar creep dislocation structures within the sub-grains. It is unclear the extent to which evolution of the sub-grain structure in this area is contributing significantly to the creep strain.

\section{4. $600 \mathrm{MPa}$ condition}

At $600 \mathrm{MPa}$ and $700 \mathrm{MPa}$ the specimens were crept to the minimum strain rate in 22 and 3 hours $(1.02 \%$ and $2 \%$ creep strain) respectively. In comparison to the $500 \mathrm{MPa}$ condition dislocation density has increased with stress. Figures $5 \mathrm{a}$ and $5 \mathrm{~b}$ show the dislocation structures formed during the $600 \mathrm{MPa}$ test. Stacking faults have become much more widely distributed in both the secondary and tertiary $\gamma^{\prime}$ as the precipitates are cut by superlattice partials, and Orowan looping is consequently reduced, Fig. 5a. In some grains slip is occurring on more than one

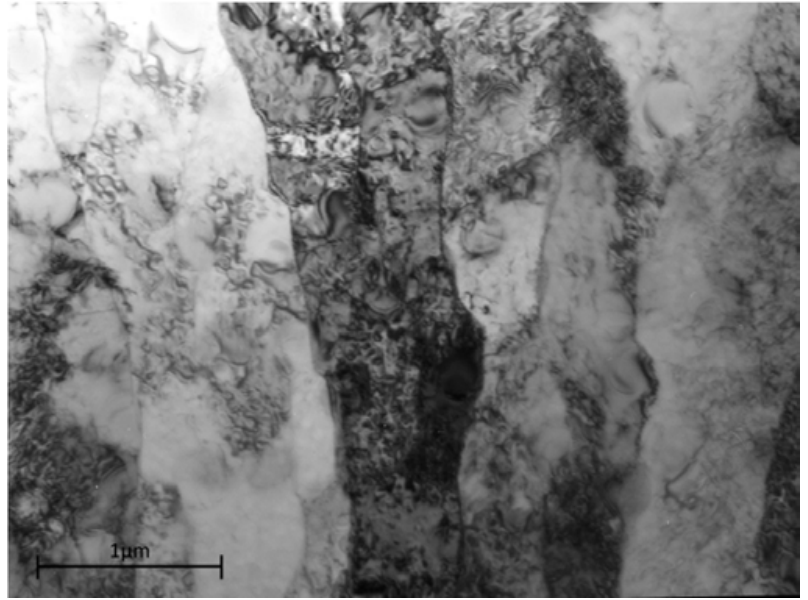

Figure 4b. Dislocation structure in Waspaloy subjected to creep loading at $500 \mathrm{MPa}$ in the GBZ.

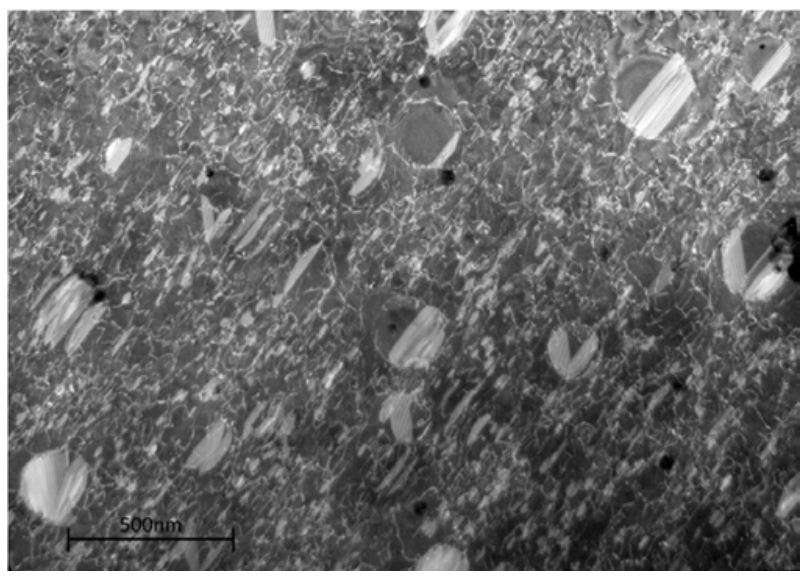

Figure 5a. Dislocation structure in Waspaloy subjected to creep loading at $600 \mathrm{MPa}$ in the grains.

slip system as evidenced by the stacking faults on a second plane.

Grain boundary zones are populated by the low angle sub-grains with dislocation banding still present at the sub-grain boundaries, as visible in Fig. 5b. The overall dislocation structure is now seemingly a combination of dislocation recovery and strain hardening processes, showing considerable changes when compared to the $500 \mathrm{MPa}$ test specimen.

\section{5. $800 \mathrm{MPa}$ condition}

The specimens crept at $700 \mathrm{MPa}$ and $800 \mathrm{MPa}$ reached the minimum strain rate in very similar times of 3 and 2 hours ( $2 \%$ and $4.4 \%$ creep strain) respectively. Similarly, the stress conditions above the yield point at 500 and $600 \mathrm{MPa}$ required 21 and 22 hours respectively.

Figures $6 \mathrm{a}$ and $6 \mathrm{~b}$ highlight the dislocation structure present in this high stress condition, $800 \mathrm{MPa}$. In the bulk of the material, the dislocation density is so great that individual processes become increasingly difficult to resolve. A second creep test was performed to only $1 \%$ strain (attained within 20 minutes) to help resolve the dislocation behaviour. 


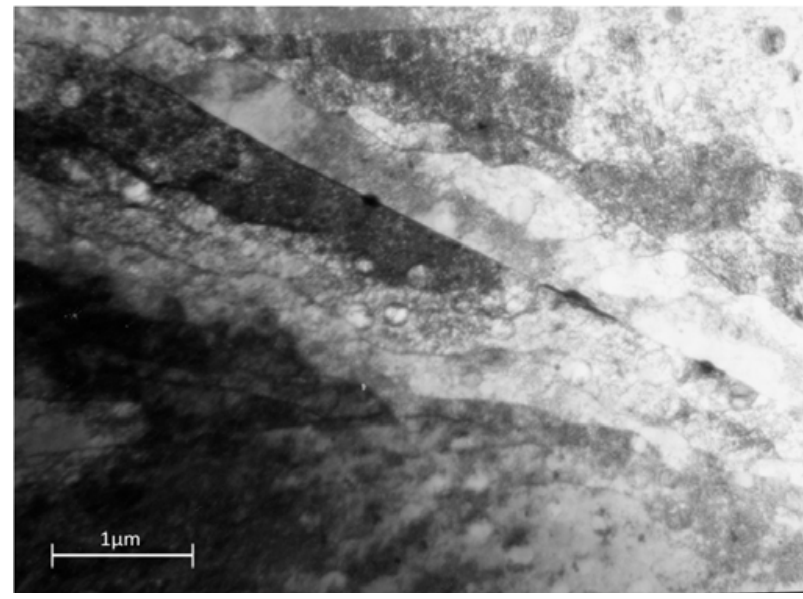

Figure 5b. Dislocation structure in Waspaloy subjected to creep loading at $600 \mathrm{MPa}$ in the GBZ.

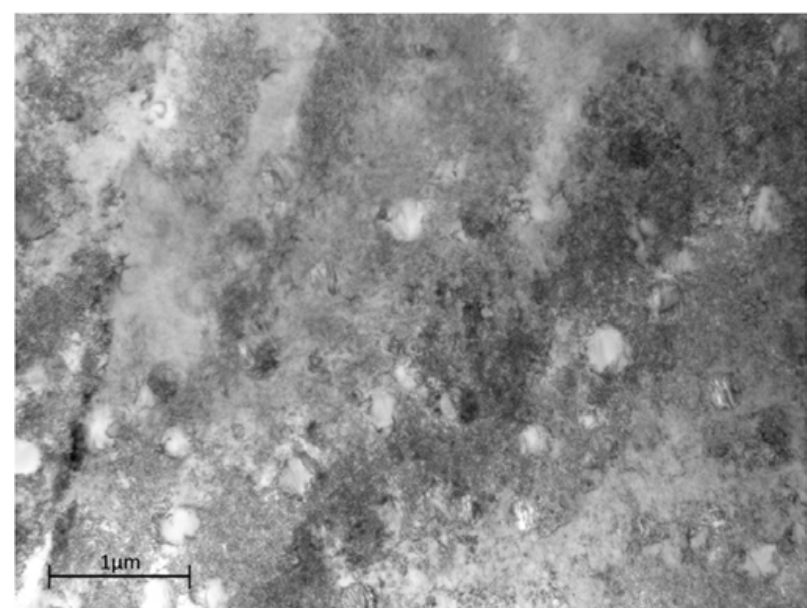

Figure 6a. Dislocation structure in Waspaloy subjected to creep loading at $800 \mathrm{MPa}$ in the grains.

Dislocations are extremely dense but mostly confined to the $\gamma$ and the tertiary $\gamma^{\prime}$ with occasional stacking faults in the secondary $\gamma^{\prime}$. These larger precipitates continue to resist cutting by lattice dislocations as observed in the tensile test to yield, Fig. 3a.

In the grain boundary zone (GBZ) the sub-grain boundaries are not distinguishable, so great is the additional dislocation density.

\subsection{Discussion}

The best fit of the creep rupture data to the Wilshire equations for Waspaloy (and many other alloys) is obtained by defining two separate linear relationships describing the high and low stress behaviour. The transition point falls naturally at the approximate yield stress of the material. This implies a change in creep behaviour associated with the yield stress as evidenced by the change in activation energy. The dislocation structures after creep above and below the yield stress do indeed show a distinct difference. Below the yield stress densities are relatively low, increasing slightly with stress, and the time to minimum creep strain is of the order of 20 hours. The pre-exisiting subgrain structure in the vicinity of

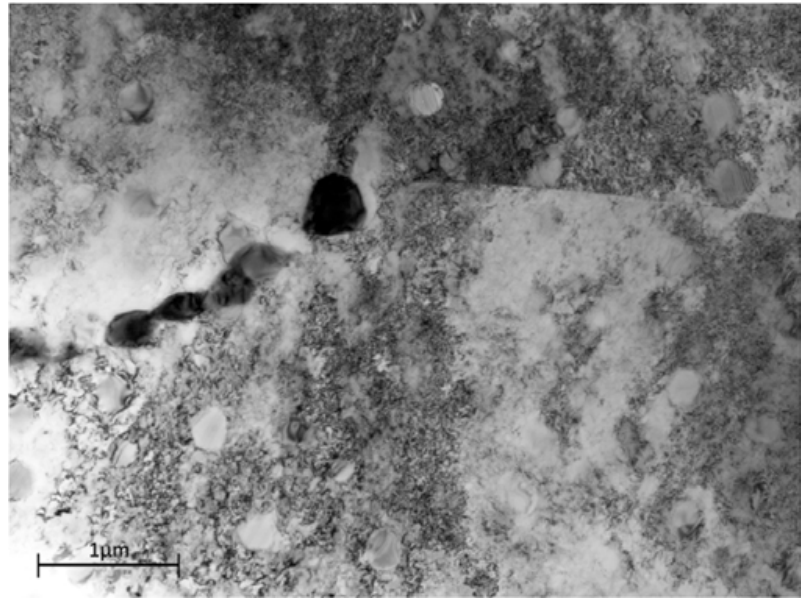

Figure 6b. Dislocation structure in Waspaloy subjected to creep loading at $800 \mathrm{MPa}$ in the GBZ.

the grain boundaries is retained. Above the yield point the dislocation density increases to the point where the dislocation spacing is closer than that of the precipitates and the sub-grain structure around the grain boundaries is obliterated by the increased density throughout. Minimum creep rates are achieved after about 20 hours. The secondary precipitates alone remain clear of all but the occasional stacking fault.

These observations can be rationalised as follows. During creep below the yield stress, the dislocation densities remain very low and the main resistance to dislocation motion is the interaction with the tertiary precipitates. At $500 \mathrm{MPa}$ the stress appears to be too low to allow cutting, even by partial dislocations trailing low energy superlattice stacking faults, let alone the higher energy APB faults. Dislocation motion is therefore limited by the climb of these dislocations over and around all but the smallest tertiary precipitates. Densities remain low as sources of new dislocations cannot be activated by stress. As the stress rises to $600 \mathrm{MPa}$ the dislocations are increasingly above the threshold for cutting by superlattice partial dislocations and the microstructure shows numerous stacking faults in the precipitates as during creep there is sufficient time to allow the reordering necessary for this to happen [9]. The minimum strain rate is probably associated with a low dislocation density and hence occurs close to the onset of tertiary creep before a gradual increase in mobile dislocation density.

Above yield the stress is sufficient for the dislocations to cut through the tertiary precipitates as in the tensile test to yield. This reveals that the process of yield is associated with the movement of dislocations to cut the tertiary precipitates which provide the principal increment of strength in a bimodal distribution of ordered precipitates [10]. The secondary precipitates are too large to cut and dislocations loop around them leaving them dislocation free. At the high strain rate in a tensile test the activated movement of partial dislocations is not possible, and the dislocations cut through the tertiary precipitates as single dislocations producing APB faults which are rectified by subsequent dislocations, i.e. "weak coupling" [11]. In the creep tests above yield the rapid 
multiplication of dislocations, triggered by the freedom of the dislocations to glide through the precipitate structure, leads to a greatly increased dislocation density and hence the increase in flow strength associated with forest hardening adding to the precipitate hardening of the virgin material. Note that the stress is still insufficient for the dislocations to pass through the secondary precipitates leaving these relatively dislocation free. At these higher stresses the minimum strain rate will occur when the dislocation multiplication rate is balanced by the recovery rate. Initially the flow rate increases due to higher mobile dislocation density, but eventually the density becomes so high that dislocations become locked in tangles lowering the creep rate. The closer spacing of the dislocations facilitates recovery until equilibrium is reached.

Based on this interpretation, the critical activation event below yield is associated with the climb of the dislocations around the $\gamma^{\prime}$ precipitates: above the yield point with the climb and recovery of dislocation tangles. The extent of dislocation interaction during the high stress regime of any material in creep is reflected in the rate of strain hardening of a material observed during monotonic tensile tests. There is a strong relationship between the apparent activation energy and the amount of strain hardening a material undergoes after yield, as evidenced by three model materials; 316 stainless steel has a very high rate of strain hardening and shows $\mathrm{Q}_{c}^{*}$ values of $250 / 150 \mathrm{~kJ} / \mathrm{mol}$ [12], Waspaloy has a medium rate of strain hardening with $\mathrm{Q}_{\mathrm{c}}^{*}$ values of $400 / 340 \mathrm{~kJ} / \mathrm{mol}$ and titanium 6-4 has a very low rate of strain hardening with negligible activation energy change, having $\mathrm{Q}_{\mathrm{c}}^{*}$ values of $250 / 250 \mathrm{~kJ} / \mathrm{mol}$ [13]. This supports the proposal that activation energy change in creep is a direct result of the increment of strain hardening: an alloy with no potential for strain hardening would not be expected to show a change in activation energy.

Hence the break which occurs during the derivation of the constants for the Wilshire equations is explained by the onset of yield changing the critical activation event for dislocation movement, rather than a change from dislocation creep to diffusional creep.

\section{Conclusion}

The following conclusions can be drawn from this programme of work:

- The best fit of the creep rupture data to the Wilshire equations for Waspaloy is obtained by two separate linear relationships separated at the yield point.
- Below yield creep takes place through the movement of dislocations controlled by diffusive climb around precipitates, whereas above yield dislocation movement is limited by forest hardening.

- The change in apparent activation energy, $\mathrm{Q}_{c}^{*}$, is directly related to the amount of strain hardening in an alloy brought about by high dislocation densities generated at stresses above yield.

- The change in activation energy, and the concomitant breaks in the Wilshire equations, are brought about by a change the mechanism controlling dislocation movement, not a complete change of mechanism.

The authors would like to thank Harshul Mathur of Cambridge University for his help and guidance using the TEM. We also acknowledge the Rolls-Royce EPSRC Strategic Partnership (EP/H500375/1 and EP/H022309/1) for support of this work and provision of materials.

\section{References}

[1] D. Allen, S. Garwood, IoMMh, London (2007)

[2] S.J. Williams, M.R. Bache, B. Wilshire, Mater. Sci. \& Tech., Vol. 26, No. 11 (2010)

[3] R.W. Evans, B. Wilshire, Creep of metals and alloys. Institue of Materials, (1985)

[4] E. Arzt, Res. Mechanica, Vol. 31 p. 399-453 (1991)

[5] O.D. Sherby, Acta Metallurgica, Vol. 10, Issue 2 (1962)

[6] Glenn S. Daehn, Holger Brehm, Huyong Lee, Byeong-Soo Lim, Mater. Sci. Eng. A, 387-389 (2004)

[7] F.R.N. Nabarro, H.L. de Villiers, The physics of creep and creep-resistant alloys. CRC Press, London (1995)

[8] Roger Reed, The Superalloys: Fundamentals and applications, Cambridge University Press (2008)

[9] R.W. Kozar, A. Suzuki, W.W. Milligan, J.J. Schirra, M.F. Savage, and T.M. Pollock; Met Trans A, 40A, (2009), p.1588-1602

[10] W. Huther and B. Reppich: Z. Metallkd., (1978), 69, p.628-34.

[11] V.A. Vorontsov, L. Kovarik , M.J. Mills, C.M.F. Rae, Acta Materialia 60, (2012) 4866-4878.

[12] M.T. Whittaker, M. Evans, B. Wilshire, Mater. Vol. 552 (2012) p. 145-150

[13] M.T. Whittaker, W.J. Harrison, R.J. Lancaster, S. Williams, Mater. Sci. Eng. A, Vol. 557, (2013) p. 114-119 